\title{
General Discussion to the Papers of Dr Girard et al., Dr Francois et al., Dr Jurascheck et al., and Dr Hackler
}

\author{
Chairman: DR J. J. WALSH
}

Dr Chantraine (Switzerland). I was very interested in the paper of Girard and his colleagues and before I ask a question I would like to say that in Liege, while I was still there, we started with Dr Onkelink's study on paraplegia immediately after the injury on the sphincter, and we continued with Dr Hachen in Geneva, and we were allowed to see the patient 3 hours after the traumatic lesion. Three hours after the cord lesion the anal sphincter and the urethral sphincter showed activity as in a normal sphincter. In IO or I 2 months of paraplegia the sphincters deteriorated sometimes, especially the anal sphincter is atrophied or shows sclerosis. Now, I was very impressed by the picture you showed with the repetition of the tapping having a decrease in the reaction of the activity. I would like to ask, were you sure that the needle was still in the sphincter?

DR GIRARD (France). We saw that response not just once but every time. We did not understand in the beginning how it was possible to obtain micturition when tapping because with the fifth tapping we could see a hyperactivity, and with this hyperactivity micturition is not possible. We showed that after many tappings, I4 or 20 or perhaps more, every time we see the hyperactivity disappears.

MR CosbIE Ross (G.B.). I was very interested in Dr Hackler's paper and I wondered whether he would think it suitable to regard children and adults in an entirely different light in this respect. As far as adults are concerned, diversion of the urine is very rarely required and when we reported 567 cases a few years ago we only found it necessary to perform the diversion in 20 adult cases. I agree with him that the main indication is the progressive renal failure associated with either progressive hydronephrosis or intractable infection or intractable obstruction, but how often does this occur? Now I would add another indication perhaps and that is the female with multiple sclerosis with continuous dribbling incontinence. I think these are cases that can be benefited by diversion of the urine. I don't usually do an ileal loop in these cases, I use the operation of Griffiths with the anteversion of the urethra. I was also interested in Dr Girard's paper and like the previous speaker, I just wonder whether one can be absolutely certain that the point of the needle is in the sphincter because there have been so many methods advocated for this particular procedure. Some people have used a plug in the urethra, even a plug in the anus, others have put in needles alongside the urethra and other people have recently used a small electrode through a urethroscope showing that, perhaps, accuracy is rather difficult to achieve in this particular procedure. I would also like to ask him whether he has correlated these findings with urethral pressure profiles. It seems to me he has correlated it apparently with cystograms but I think it is absolutely vital if this is to be a valuable procedure for it to be correlated with urethral profiles.

Dr J. J. Walsh (Chairman). May I just follow on. I was very pleased that $\mathrm{Mr}$ Cosbie Ross raised the point of the female patient. We have done two ileal loops in males over a period of some 30 years, but our main indication for ileal loop is the female patient who has had an indwelling catheter for 10 or 15 years and has a urethra through which you can see the ureteric orifices from outside, and all attempts by very many distinguished surgeons to repair that urethra or narrow it down have not been successful. This is one indication for ileal loop that we've found.

DR HACKLER (U.S.A.). A paper can only be given in a very short span. We are quite conservative in recommending this procedure. The McGuire V.A. Hospital is a rather large Spinal Cord Centre with I70 beds, and I really can't tell you how many admissions have been coming to there since 1940. But anyway, we do about two a year and only 44 have been performed since 1960 when the first one was performed. So 
that tells how often we do it, which is as seldom as possible because it is a rather major surgical procedure, and we go to great pains to try to rehabilitate his bladder which may be getting too spastic, too thickwalled, and the ureters are getting pinched down by the muscle or either they've got pretty bad reflux. Even going so far as recommending rhizotomy on occasion but as you know the patient doesn't go along with this too often because of the adverse effect on potency. I think that was a good point, how many of the children were really infants with bad muscle in their ureters to start with and, of course, children have probably more complications because of a high incidence of ileal stenosis.

Dr Sussmann (U.S.A.). I will try to say as tactfully as I can, but it seemed to me that you have a 25-year operating mortality figure of 49 per cent and if we look at that figure, that figure by any other series that I am familiar with would be about double what it ought to be.

DR SILVER (G.B.). Dr Girard said quite clearly that there was a different reaction in the electromyelography of the anal sphincter to the urethral sphincter. Now as I understand it, all the early papers from Blen and Bors were saying that you could take the anal sphincter as representative of the urethral sphincter. Have we now always to do both sphincters if we are going to do electromyelography?

DR GIRARD (France). It is always the question are we in the urethral sphincter when we are making an EMG ? We made an experiment with an X-ray television, we introduced Lipiodol in the urethra and we saw that we were in the urethral sphincter; we saw also variations of activity during the examination. In particular, we are sure that we see the variations when filling the bladder and suddenly there is a hyperactivity that appears. As far as ureter profiles are concerned, we do not do that. This examination is done usually and we do also a cystometry. Yes, ureter and anal sphincters have the same reactions but not always, and I told you in cases of TI2 and LI lesions we saw no flaccidity in the urethral sphincter but some reflex activity just in the anal sphincter and we saw that not just once but many times.

Dr Agerholme (G.B.). If I might go back to the ileal diversion, I am concerned more with spinal bifida, multiple sclerosis than spinal cord injuries, but it has been quoted in the same context; little mention was made of actual success of diversion. Success of diversion may be obvious in the straightforward paraplegic but in the child field it is by no means as successful, it may be initially a successful diversion and seem a satisfactory conclusion but as these deformed spines grow you get a very unsuccessful diversion and all you have done in fact is to cause urine to run out on the abdominal wall in complete uncontrol because you cannot fit the appliances, and it is a major disaster. Many parents would prefer, so would their children, to have the urine in the perineal area rather than on the abdominal wall, and there is I am sure some relationship to whether there is sensation in the skin area on to which it opens, and I don't think sufficient attention has been paid to this. I find that a diversion which can be managed if a person has good hands is very much more successful in the long term than one where for various reasons the hands are poor.

Dr HACKLER (U.S.A.). I certainly agree about the meningomyelocele and I just want to make one statement concerning mortality. This was not an operating mortality. This study was started by Dr Bunts and Dr Hutch 1949-50, they picked the patients out so all I can say it is a perspective study; we followed these patients and I know it comes back to approximately 50 per cent mortality in 25 years. I know everybody reports much better than that but most are retrospective studies.

Chairman. My real question is do you consider that a diverticulum is an indication for operation without narrowing?

DR Dollfus (France). If it causes infection and if it causes stones, yes. 